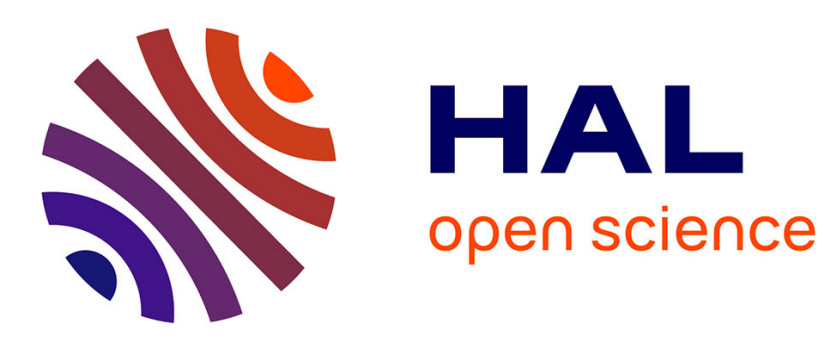

\title{
Index of efficiency for strength-grading machines for solid wood
}

Guillaume Roblot, Laurent Bleron, Frédéric Mothe, Robert Collet

\section{To cite this version:}

Guillaume Roblot, Laurent Bleron, Frédéric Mothe, Robert Collet. Index of efficiency for strengthgrading machines for solid wood. European Journal of Environmental and Civil Engineering, 2013, 17 (4), pp.263-269. 10.1080/19648189.2013.783417 . hal-00879742

\section{HAL Id: hal-00879742 \\ https://hal.science/hal-00879742}

Submitted on 27 Nov 2013

HAL is a multi-disciplinary open access archive for the deposit and dissemination of scientific research documents, whether they are published or not. The documents may come from teaching and research institutions in France or abroad, or from public or private research centers.
L'archive ouverte pluridisciplinaire HAL, est destinée au dépôt et à la diffusion de documents scientifiques de niveau recherche, publiés ou non, émanant des établissements d'enseignement et de recherche français ou étrangers, des laboratoires publics ou privés. 


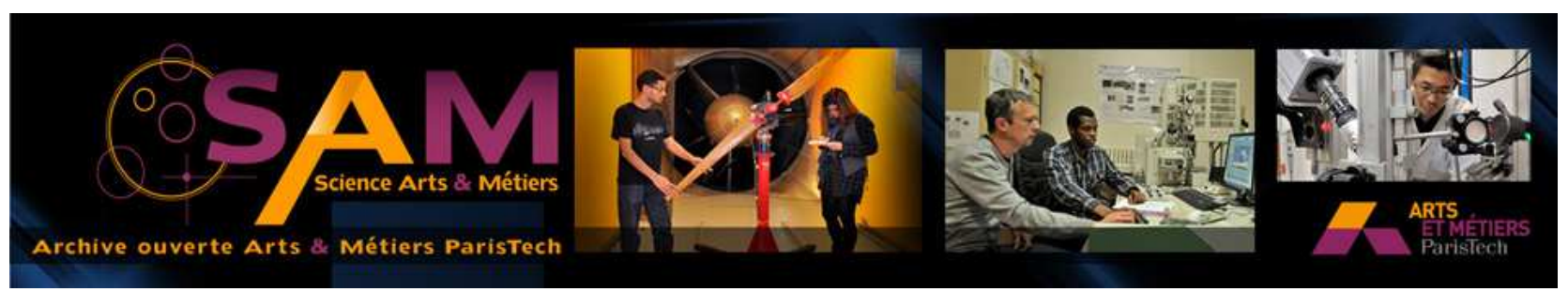

Science Arts \& Métiers (SAM)

is an open access repository that collects the work of Arts et Métiers ParisTech researchers and makes it freely available over the web where possible.

This is an author-deposited version published in: http://sam.ensam.eu

Handle ID: .http://hdl.handle.net/10985/7456

\section{To cite this version :}

Guillaume ROBLOT, Laurent BLERON, Frédéric MOTHE, Robert COLLET - Index of efficiency for strength-grading machines for solid wood - European Journal of Environmental and Civil Engineering - Vol. 17, n4, p.263-269 - 2013 


\title{
Index of efficiency for strength-grading machines for solid wood
}

\author{
Guillaume Roblot ${ }^{\mathrm{a} *}$, Laurent Bleron ${ }^{\mathrm{b}}$, Frederic Mothe ${ }^{\mathrm{c}}$ and Robert Collet ${ }^{\mathrm{b}}$ \\ ${ }^{a}$ LuxScan Technologies, Weinig Group, L-4384, Ehlerange, Luxembourg; ${ }^{b}$ LaBoMaP, Groupe \\ Matériaux et Usinage Bois, Arts et Métiers ParisTech, Centre de Cluny, F-71250 Cluny, France; \\ 'INRA, UMR1092 Laboratoire d'Etude des Ressources Forêt-Bois, F-54280 Champenoux- \\ AgroParisTech, UMR 1092 LERFoB, F-54000 Nancy, France
}

\begin{abstract}
The settings of strength-grading machine for structural pieces of wood are checked according to the EN 14081 standard. However, different machines have different performances depending on the accuracy of the estimation of the board's properties, and there is no easy way to compare the efficiency of these machines especially if the machine does not use the same sampling. In this paper, we introduce an index called index of efficiency for grading machines. This parameter is in the range of $0-100 \%$ and allows to compare performances of different machines for a given set of grades. The computation of this index is based on the cost matrix method of the EN 14081 and requires to have the size matrix of a setting to be computed.
\end{abstract}

Les réglages des machines de classement mécanique des bois de structure sont établis en accord avec la norme EN 14081. Cependant, en fonction de la précision de l'estimation des propriétés mécaniques, les machines auront des performances différentes. Il n'y a toutefois pas de méthode simple pour comparer l'efficience de ces différentes machines surtout si elles ne sont pas étalonnées avec le même échantillonnage. Dans cet article, nous introduisons un indice que nous appelons indice d'efficience pour machines de classement. Cet indice variant de 0 à $100 \%$ permet de comparer les performances de différentes machines pour une combinaison de classes donnée. Le calcul de cet indice est basé sur la méthode de la matrice coûts de l'EN 14081 et nécessite la connaissance de la matrice de contingence de chaque machine.

Keywords: structural wood; strength grading; machine grading; efficiency; performance

Mots-clés: bois de structure; classement mécanique; efficience; performance

\section{Introduction}

Sawn timbers that will be used as part of a structure in Europe now have to be graded according to their strength and stiffness. Thanks to this grading, buildings can be safely designed by following the Eurocode 5 rules. The grading of solid wooden boards can be done by two main ways: the visual strength grading and the machine strength grading. The visual strength grading has the advantage of being quite cheap to set up, as far as the volume of wood to be graded is not too high. The efficiency of this grading is however very low (Roblot et al., 2008). On the other hand, the machine grading gives 
much better results even if the initial investment is much higher. This is especially true for high grade like C30, which can be seen in Table 1 .

Machines which are used for grading solid wooden boards in Europe have to fulfil the requirements of the EN 14081 standard. This standard gives a set of rules that need to be followed and that allow computing limits on the indicative properties (IP) for each wanted grade. The IP is usually a combination of different non-destructive parameters given by the machine (e.g. density, dynamic modulus of elasticity, Knot Area Ratio, etc.). This standard is however quite complex to understand. This is especially the case for customers of grading machines, who are not always familiar with the required statistical knowledge. In the EN 338 standard, grades are defined and called with a letter (C for softwood) and a number (characteristic bending strength) for example C30 or C18. Machine settings are actually computed for a given set of grade (for example, C30/C24/ C18/Rejected). The reader has to keep in mind that for different sets of grade, a given machine can have various levels of efficiency. For example, Figure 1 shows the thresholds on the IP of the same machine for two different sets of grades (C30/C18/Rejected and $\mathrm{C} 18$ /Rejected).

One can see that some boards, which were graded in C18 in the C18/Rejected set, are rejected in the $\mathrm{C} 30 / \mathrm{C} 18 /$ Rejected set. Moreover, machines using different technologies (vibration analysis, ultrasound, x-rays scanning, optical scanning, etc.) will give different results on the same batch of boards. The efficiency of simple machines can for example be good for low grades or for sets with few grades, but this same machine can be very bad for the grading into higher grades. However, the standard only provides with the thresholds on the IP values (part four of EN 14081), which guaranties the limitation of the upgrading but does not give any information on the efficiency of the machines. That is why we introduce in this paper an index that describes the level of

Table 1. Results of strength grading for optimal, best machine and visual grading on French Douglas-fir boards (Reuling et al., 2008).

\begin{tabular}{lccc}
\hline Grades & Optimal (\%) & Machine (\%) & Visual (\%) \\
\hline C30 - STI & 70 & 44 & 11 \\
C18 - STIII & 20 & 36 & 50 \\
Reject & 10 & 20 & 29 \\
\hline
\end{tabular}
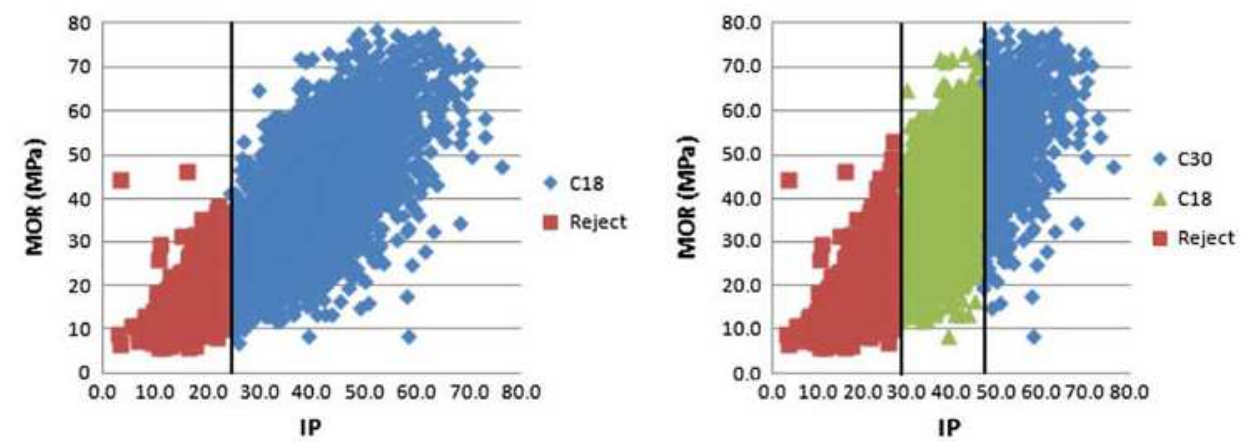

Figure 1. Modules of rupture (MOR) and indicative properties (IP) measured on boards of spruce and IP thresholds computed according to EN 14081 for two sets of grades (C18/Rejected and $\mathrm{C} 30 / \mathrm{C} 18 /$ Rejected). One can see that thresholds for $\mathrm{C} 18$ are different in $\mathrm{C} 18 /$ Reject and C30/C18/Reject set. 
efficiency of a machine, and that can be used to compare different machines for a given set of grades.

\section{Methods}

\subsection{Grading process of the $\mathrm{EN} 14081$}

The grading according to the EN 14081 standard is done by batch. This means that grades are not computed for one board but for a batch of boards. Basically, the batch of boards has to have fifth percentiles of density, fifth percentiles of module of rupture (MOR) and average module of elasticity (MOE) above the given limits. These limits are defined in EN 338 and computed according to EN 384 specifications.

Moreover, grading has to fulfil the cost matrix method, which has been introduced in Rouger $(1996,1997)$ and is now part of the EN 14081 standard. In this method, the grading results are compared to the results of a perfect machine that could give to each board its optimal grade. The optimal grades are computed according to EN 384 and an algorithm that allows computing the optimal grading, which can be found in the annex of Rouger (1997). Each downgraded and upgraded case gets a different weight. These weights are used to limit the amount of upgraded boards.

The starting point of this method is to build a size matrix which is a double-entry table comprising optimal grade vs. assigned grade. Table 2 is the size matrix of the example presented in the EN 14081 standard. Then, a global cost matrix is build, resulting by dividing each cell of the size matrix by the total number of boards on the assigned grade (sum of the column) and multiplying it by the corresponding term in elementary cost matrix.

The elementary cost matrix is composed of weights for each pair of optimal and assigned grade. The elements above the diagonal describe the cost of downgraded boards and the elements below the diagonal describe the safety risk of upgraded boards. Upgrading creates a safety risk since the upgraded boards too much may be loaded relative to their real strength. The elements above the diagonal are computed by taking into account the corresponding failure probabilities. The consequence of downgrading boards is to increase the amount of wood used for the design of a construction. Assuming that boards are dimensioned according to the deformations, which is related to the height of the board with a power of 3 , the cost of the downgrading can be computed according to Equation (1) (Rouger, 1997).

$$
\operatorname{Cost}_{\text {downgrading }}(\text { optimal, assigned })=\sqrt[3]{\frac{\mathrm{MOE}_{\text {optimal }}}{\mathrm{MOE}_{\text {assigned }}}-1}
$$

Table 2. Example size matrix of EN 14081-2. This matrix presents the reparation of boards according to their optimal grades and assigned grades. The assigned grade corresponds to the grade given by the machine.

\begin{tabular}{lrrrr}
\hline & \multicolumn{4}{c}{ Assigned grade } \\
\cline { 2 - 5 } Optimum grade & C35 & C27 & C22 & Reject \\
\hline C35 & 207 & 32 & 16 & 2 \\
C27 & 10 & 168 & 12 & 1 \\
C22 & 4 & 13 & 84 & 2 \\
Reject & 0 & 2 & 2 & 24 \\
\hline
\end{tabular}


In the EN 14081, these weights are multiplied by 10 in order to give more readable values. For example, the case C35 optimal grade with $\mathrm{C} 27$ assigned grade gets a weight of 0.42 and C35 optimal grade with C22 assigned grade gets 0.91 . The second weight is higher because the cost loss is higher in the second case. For the rejected grades, it is a bit more complex since they have no characteristic values. The characteristics of the rejected boards depend actually a lot on the lower grade of the set, for example, boards rejected for $\mathrm{C} 22$ while probably have higher properties than boards rejected from the C18 grade. That is why it was decided to use $75 \%$ of the characteristic values of the grade from which the board is rejected (EN 14081, 2005). For example in a C35/C27/ C22/Rejected grade set, the characteristics value for rejected class would be $75 \%$ of the characteristics value of $\mathrm{C} 22$.

According to EN 14081, the setting of the machine is valid if the terms below the diagonal of the global cost matrix (upgraded boards) are lower than 0.2 and there is no limit to the downgrading cases. From these rules, it is possible to compute the different thresholds on the IP of the machine for each set of grades. More detailed description of a setting build can be found in Bengtsson et al. (2003), Köhler (2006), and Köhler and Steiger (2006). However, the standard only provides with the thresholds on the IP values and not the size matrices of the machines. The size matrix could have been used to compare different machines. Moreover, even with the size matrix, it is not easy to compare different machines since comparing two tables is not an easy task. That is why we wanted to introduce an index of efficiency (IE).

\subsection{Index of efficiency}

We decided to call the index which is described below, the IE for grading machines. To make it easily understandable and usable, we decided to build an index varying between 0 and $100 \%$. The closer to $100 \%$ the index is, the better the efficiency of the machine is. The index can only allow comparing machines on the same set of grades. Since we previously saw that a machine can have very different behaviours with different set of grades, it does not really make sense to compare different machines on different set of grades.

The method we used to build our index is based on the cost matrix method, with some adjustments to get an index fitting with our requirements. First of all, since the number of upgraded boards is limited by the standard itself, we decided not to penalise compliant machines for upgrading boards. To do this, the size matrix will be modified in order to consider upgraded boards as correctly graded. Table 3 is the size matrix of the EN 14081-2 example modified in that way (theoretical approach). We will now call this matrix the efficiency size matrix.

Then, we compute a modified global cost matrix. Instead of using the total number of boards in the assigned grade (sum of columns), we use the total number of boards in the optimal grade (sum of rows). We are actually interested here in the efficiency of the machine and not in the cost of the downgrading. We are also using a modified elementary cost matrix (Table 4) computed by dividing the elementary cost matrix of EN 14081 by the maximum value of the upper part of the diagonal. The maximum value is 4.5 and corresponds to a C50 board rejected from C14 grade. We finally take the complementary to 1 of the computed value in order to get higher weights for well-graded boards and lower for downgraded boards. This is done in order to get an index of 0 for bad machines and 100 for perfect ones. This matrix is what we call the efficiency elementary weight matrix, since we cannot really speak anymore of costs. A supplemental 
matrix (Table 5) was built for the rejected grades since, according to the definition mentioned above, the cost of downgrading depends on the considered set of grades.

The global efficiency matrix (Table 6) can now be computed for any set of grades using both Tables 4 and 5 to get the needed weights. These weights are printed in bold

Table 3. Efficiency size matrix of the EN 14081-2 example. Like the size matrix, this matrix presents the repartition of the boards between grades, but upgraded boards have been moved to the correct grade.

\begin{tabular}{lrrrr}
\hline & \multicolumn{4}{c}{ Assigned grade } \\
\cline { 2 - 5 } Optimum grade & C35 & C27 & C22 & Reject \\
\hline C35 & 207 & 32 & 16 & 2 \\
C27 & 0 & 178 & 12 & 1 \\
C22 & 0 & 0 & 101 & 2 \\
Reject & 0 & 0 & 0 & 28 \\
\hline
\end{tabular}

Table 4. Efficiency elementary weight matrix. These weights are the normalized complementary to 1 of the element of the elementary cost matrix of the EN 140181. The weights used in our example are printed in bold.

\begin{tabular}{|c|c|c|c|c|c|c|c|c|c|c|c|c|}
\hline Assig. Optim. & $\mathrm{C} 50$ & $\mathrm{C} 45$ & $\mathrm{C} 40$ & $\mathrm{C} 35$ & $\mathrm{C} 30$ & $\mathrm{C} 27$ & $\mathrm{C} 24$ & $\mathrm{C} 22$ & $\mathrm{C} 20$ & $\mathrm{C} 18$ & $\mathrm{C} 16$ & $\mathrm{C} 14$ \\
\hline $\mathrm{C} 50$ & 1.00 & 0.95 & 0.90 & 0.84 & 0.78 & 0.74 & 0.70 & 0.62 & 0.58 & 0.53 & 0.42 & 0.29 \\
\hline $\mathrm{C} 45$ & & 1.00 & 0.95 & 0.89 & 0.83 & 0.79 & 0.76 & 0.68 & 0.63 & 0.59 & 0.48 & 0.36 \\
\hline $\mathrm{C} 40$ & & & 1.00 & 0.94 & 0.88 & 0.85 & 0.81 & 0.74 & 0.69 & 0.65 & 0.54 & 0.42 \\
\hline $\mathrm{C} 35$ & & & & 1.00 & 0.94 & 0.91 & 0.87 & 0.80 & 0.76 & 0.71 & 0.61 & 0.49 \\
\hline C30 & & & & & 1.00 & 0.97 & 0.93 & 0.86 & 0.82 & 0.78 & 0.68 & 0.56 \\
\hline C27 & & & & & & 1.00 & 0.97 & 0.89 & 0.85 & 0.81 & 0.71 & 0.60 \\
\hline $\mathrm{C} 24$ & & & & & & & 1.00 & 0.93 & 0.89 & 0.85 & 0.75 & 0.64 \\
\hline $\mathrm{C} 22$ & & & & & & & & 1.00 & 0.96 & 0.92 & 0.83 & 0.72 \\
\hline $\mathrm{C} 20$ & & & & & & & & & 1.00 & 0.96 & 0.87 & 0.76 \\
\hline $\mathrm{C} 18$ & & & & & & & & & & 1.00 & 0.91 & 0.81 \\
\hline $\mathrm{C} 16$ & & & & & & & & & & & 1.00 & 0.90 \\
\hline $\mathrm{C} 14$ & & & & & & & & & & & & 1.00 \\
\hline
\end{tabular}

Table 5. Efficiency elementary weight for rejected grade. Like the elementary cost matrix elements, these weights have to be computed according to the class from which the boards are rejected. The weights used in our example are printed in bold.

\begin{tabular}{|c|c|c|c|c|c|c|c|c|c|c|c|c|}
\hline $\begin{array}{l}\text { Reject from } \\
\text { Optim. }\end{array}$ & C50 & $\mathrm{C} 45$ & $\mathrm{C} 40$ & C35 & $\mathrm{C} 30$ & $\mathrm{C} 27$ & $\mathrm{C} 24$ & $\mathrm{C} 22$ & $\mathrm{C} 20$ & $\mathrm{C} 18$ & $\mathrm{C} 16$ & $\mathrm{C} 14$ \\
\hline C50 & 0.78 & 0.72 & 0.67 & 0.60 & 0.53 & 0.49 & 0.45 & 0.36 & 0.31 & 0.26 & 0.14 & 0.00 \\
\hline C45 & & 0.78 & 0.72 & 0.66 & 0.59 & 0.55 & 0.51 & 0.42 & 0.37 & 0.32 & 0.21 & 0.07 \\
\hline C40 & & & 0.78 & 0.72 & 0.65 & 0.61 & 0.57 & 0.49 & 0.44 & 0.39 & 0.27 & 0.14 \\
\hline C35 & & & & 0.78 & 0.71 & 0.67 & 0.64 & 0.55 & 0.51 & 0.46 & 0.35 & 0.22 \\
\hline C30 & & & & & 0.78 & 0.74 & 0.70 & 0.62 & 0.58 & 0.53 & 0.42 & 0.29 \\
\hline C27 & & & & & & 0.78 & 0.74 & 0.66 & 0.62 & 0.57 & 0.46 & 0.34 \\
\hline $\mathrm{C} 24$ & & & & & & & 0.78 & 0.70 & 0.65 & 0.61 & 0.50 & 0.38 \\
\hline $\mathrm{C} 22$ & & & & & & & & 0.78 & 0.73 & 0.69 & 0.59 & 0.47 \\
\hline $\mathrm{C} 20$ & & & & & & & & & 0.78 & 0.73 & 0.63 & 0.51 \\
\hline C18 & & & & & & & & & & 0.78 & 0.68 & 0.56 \\
\hline C16 & & & & & & & & & & & 0.78 & 0.67 \\
\hline C14 & & & & & & & & & & & & 0.78 \\
\hline
\end{tabular}


Table 6. Global efficiency matrix of the EN 14081-2 example. The element of this matrix are the product terms by terms of the efficiency size matrix by the corresponding efficiency weights divided by the number of boards in the corresponding optimal grade.

\begin{tabular}{lcccr}
\hline & \multicolumn{4}{c}{ Assigned grade } \\
\cline { 2 - 5 } Optimum grade & C35 & C27 & C22 & Reject \\
\hline C35 & 0.805 & 0.113 & 0.050 & 0.004 \\
C27 & & 0.932 & 0.056 & 0.003 \\
C22 & & 0.981 & 0.015 \\
Reject & & & & 1.000 \\
\hline
\end{tabular}

in Tables 4 and 5. For example, the cell corresponding to optimum grade $\mathrm{C} 27$ and assigned grade $\mathrm{C} 22$ can be computed according to Equation (2):

$$
\operatorname{GEM}_{(\mathrm{C} 27, \mathrm{C} 22)}=\frac{12}{178+12+1} \times 0.89=0.056
$$

At the end, the IE is computed according to Equation (3). In our example, the number of grade is four, which gives an index of $97.99 \%$ to the machine.

$$
\mathrm{IE}=\max \left(0,\left(\frac{\sum_{i, j} \operatorname{GEM}(i, j)}{\text { Number of grade }}-0.50\right) \times 2\right)
$$

\section{Discussion and conclusion}

The IE presented in the previous paragraph was designed for varying in the range $0-100 \%$. The index is actually truncated to $50 \%$ in order to amplify its variations, considering that machines with a not truncated index below $50 \%$ would anyway be very bad. On the other hand, a machine that would give its optimal grade to every board will get a $100 \%$ index as expected.

Another point that could lead to discussion is the way we are dealing with upgraded boards. One could think that upgraded boards should decrease the index of a machine, since upgraded boards are a safety risk for buildings. However, since upgrading is limited by the standard and moreover involved in the Eurocode calculation, we think that a good machine is one that gives the best grading possible as far as it follows the standard rules. Actually, upgraded boards could be a problem if the settings were done based on a board by board grading. However, since the standard is working on batches, the upgrading is not an issue.

Anyway, if one wants to get an index describing the reliability of the machine prediction rather than the efficiency, it is still possible to adapt the method. It is possible for example to use the standard size matrix instead of the efficiency size matrix, for the computation of the index. This way, upgraded boards will not give any point to the index, which means that the index will decrease. With this method, the example machine will get a reliability index of $79.98 \%$.

We have presented an index based on EN 14081 specifications that allows both the quantifying of the efficiency level of a grading machine and the comparison of different machines together. As it is quite difficult to achieve the comparison due to the difference of sampling, this index can be used in research works in order to quantify the 
effect of machines improvements, or by consumers who want select the machine that best fits their needs. However, the fact that the size matrix of the machines is not jointed to the standard compliance certificate is still an issue for machine customers, which will have to claim this information from the manufacturers, assuming they are ready to give it.

\section{References}

Bengtsson C., \& Fonselius M. (2003). Settings for strength grading machines - Evaluation of the procedure according to prEN 14081, part 2. Proceedings of the 36th Meeting, International Council for Research and Innovation in Building and Construction, Working Commission W18 - Timber Structures, CIB-W18, Paper No. 36-5-1, Colorado, USA.

EN 14081. (2005). Timber structures - Strength graded structural timber with rectangular cross section. Brussels: Comité Européen de Normalisation.

EN 338. (2003). Structural timber - Strength classes. Brussels: Comité Européen de Normalisation.

EN 384. (2003). Structural timber - Determination of characteristic values of mechanical properties and density. Brussels: Comité Européen de Normalisation.

Köhler J. (2006). Reliability of timber structures (Dissertation ETH No. 16378). Swiss Federal Institute of Technology, Zurich, Switzerland.

Köhler J., \& Steiger R. (2006). A discussion on the control of grading machine settings - Current approach, potential and outlook. Proceedings of the 36th Meeting, International Council for Research and Innovation in Building and Construction, Working Commission W18 - Timber Structures, CIB-W18, Paper No. 39-5-1, Florence, Italy.

Reuling, D., Lanvin, J. D., \& Rouger, F. (2008). Homologation des machines de classement des bois pour la résistance. Colloque sur le classement structure des sciages par machine (pp. 24-39). France: Dompierre les Ormes.

Roblot, G., Coudegnat, D., Bleron, L., \& Collet, R. (2008). Evaluation of the visual stress grading standard on French spruce (Picea excelsa) and Douglas-fir (Pseudotsuga menziesii) sawn timber. Annals of Forest Science, 65, 4.

Rouger, F. (1996). Application of a modified statistical segmentation method to timber machine strength grading. Wood Fiber Science, 28, 438-449.

Rouger, F. (1997). A new statistical method for the establishment of machine settings. Proceedings of the 30th Meeting, International Council for Research and Innovation in Building and Construction, Working Commission W18 - Timber Structures, CIB-W18, Paper No. 30-17-1, Vancouver, Canada. 